\title{
Penicilloyl-polylysine intradermal testing for penicillin hypersensitivity
}

\author{
JOHN W. LENTZ* AND LESLIE NICHOLAS ${ }^{\star \star}$ \\ From the Venereal Disease Control Section, Community Health Services, Philadelphia
}

The immunochemical mechanisms involved in penicillin allergy have been the subject of numerous investigations during the past 10 years. Considerable progress in understanding how patients become sensitized to penicillin has been made since the publications by Levine (1960) and Weck and Eisen (1960) on various antigenic determinants involved in contact hypersensitivity to penicillin as well as the immunological properties of penicillanic acid, an antigenic derivative of penicillin. Also noteworthy have been the independent investigations of Levine and Ovary (1961), Parker, Weck, Kern, and Eisen (1962a), Parker, Shapiro, Kern, and Eisen (1962c), and Weck (1962a) in establishing the penicilloyl group as the major antigenic determinant involved in hypersensitivity to penicillin. These investigators have shown that rabbits immunized with penicillin form anti-penicilloyl antibodies, which are detectable by precipitation, passive cutaneous anaphylaxis, and haemagglutination. Levine and Ovary (1961) reported specific skin reactions to the intradermal injections of penicilloyl-human gamma globulin conjugate in three out of six patients with histories of penicillin allergy. The specificity of these skin reactions was confirmed by their inhibition with an excess of penicilloyl-epsilonaminocaproate. Parker and others (1962c), Weck (1962b), and Weck and Blum (1963) shortly thereafter reported similar results, using penicilloyl-polylysine conjugates as the test material in a large number of patients.

Received for publication March 2, 1970

Read before the Section of Dermatology, AMA 118th Annual Convention in cooperation with the American Venereal Disease Association, New York City, July 16, 1969.

Reprint requests to Venereal Disease Control Section, Division of Epidemiology, Community Health Services, 500 South Broad Street, Philadelphia, Pa. 19146, U.S.A.

^Assistant Professor of Dermatology, Jefferson Medical College and Hospital; Chief of the Section of Venereal Disease Control, Division of Epidemiology, Community Health Services, Philadelphia Department of Health.

$\star \star$ Clinical Professor of Medicine (Dermatology), Hahnemann Medical College and Hospital, Venereal Disease Program Specialist, Division of Epidemiology, Community Health Services, Philadelphia, Department of Health.

\section{Patients studied}

The present, prospective study was conducted in a large venereal disease clinic population that was frequently exposed to therapeutic penicillin, and in which a known adverse reaction rate to therapeutic penicillin was available. All individuals admitted to this study were seen in the largest venereal disease clinic in Philadelphia. They were predominantly of one ethnic group, and their ages varied from 17 to 87 years. Many of them had had previous treatment with penicillin on numerous occasions. Since much of the validity of skin testing depends on the technical competence of the individuals who perform, read, and interpret the skin reactions, in our study, only two physicians administered the penicilloyl-polylysine (PPL) intradermal test, and then read and recorded the results. Not all of the patients received penicillin, for one or more of the following reasons: No clinical indication for treatment; a positive PPL skin test; a history of penicillin hypersensitivity; refusal to accept intramuscular therapy; or a combination of any of these factors.

\section{Material}

The PPL preparation ${ }^{\star}$ employed for skin testing in this study is sterile, is supplied in single dose ampoules, and requires storage under refrigeration. The manufacturer describes this conjugate as having an average molecular weight of 14,000 as determined by viscosity measurements and percentage substitution of at least 55 per cent. The preparation as used contains $6 \times 10^{-5} \mathrm{M}$ penicilloyl in $0.01 \mathrm{M}$ phosphate buffer and $0.15 \mathrm{NaCl}$ at $\mathrm{PH} 7.4$ as determined by mercuric chloride titration using a molar extinction coefficient of 22,325. Kinetic studies on the rate of degradation of the penicilloyl moiety were supplied by the manufacturer. The observed rate constant $\mathrm{K}$ at $40^{\circ} \mathrm{C}$. is $4.37 \times 10^{-4}$ per day.

0.03 of $1 \mathrm{ml}$. of the test material were given intradermally and the wheal formation was read in 20 minutes.

For practical reasons, skin reactions were evaluated as follows:

Negative: No increase in size of the initial bleb.

Positive: definite increase in the size of the original bleb. Ambiguous : very slight indefinite increase in size of the original bleb.

*Supplied by the Kremers-Urban Company, Milwaukee, Wisconsin, as Pre-Pen (R) under IND No. 2135. 
The occasional erythematous flare which developed in some patients was ignored because of its inconsistency. Permanent impressions of the skin reactions were obtained by outlining the initial bleb and any resulting wheal with a fine ball-point pen and transferring the outline to scotch tape which was then attached to the patient's record.

More than 8,000 skin tests have been performed with several preparations, since our programme of intradermal testing with PPL for penicillin hypersensitivity was begun in 1965. This presentation, however, is limited to the reagent described above which was introduced in August, 1966, and used exclusively thereafter.

This preparation has been observed to give excellent and distinct skin responses. Sharp positive cutaneous reactions frequently manifested by pseudopod formation and equally definite negative reactions were characteristic. The number of ambiguous intradermal tests in this series was an insignificant 0.7 per cent. of the test population as compared with a much greater incidence with earlier preparations. The earlier PPL conjugates initially used, were prepared with a polylysine of high molecular weight (over 50,000) with a percentage conjugation of 22. Parker, Kern, and Eisen (1962b) and Parker and others (1962a, b) have shown unsubstituted polylysines to be urticariogenic, and the large number of unsubstituted $\mathrm{NH}_{2}$ groups in these preparations undoubtedly contributed to the high number of ambiguous reactions encountered. These preparations were also contaminated with additional degradation products which may interfere with the antigen-antibody reaction and result in equivocal skin reactions.

Since the beginning of the PPL skin test programme, we have observed far fewer instances of hypersensitivity to therapeutic penicillin in the study population. Before its inauguration the therapeutic penicillin reactor rate was 3.5 per cent., ${ }^{\star}$ but it has since been limited to about one-tenth of 1 per cent.

This dramatic drop in adverse reactions to penicillin may not be due entirely to the use of the skin test. Other factors which may have acted concomitantly to account for this decrease include more meticulous care in history taking; avoidance of chancing penicillin therapy in patients with histories of penicillin hypersensitivity even though the intradermal tests were negative; and not challenging with penicillin many patients with positive skin tests particularly those with strong responses.

*1964 Penicillin Reaction Study conducted by the Venereal Disease Program, NCDC, PHS, Atlanta, Georgia (unpublished)

\section{Method of study}

The patients were divided into three groups (Table I) according to their history of previous penicillin therapy and sensitivity. Penicillin sensitivity, hypersensitivity, and allergy, which are used interchangeably, include all patients reporting angioneurotic oedema, urticaria, generalized pruritus, erythematous maculopapular eruptions, and anaphylactic reactions.

GROUP I These patients had received previous penicillin therapy but had shown no evidence of hypersensitivity to the antibiotic.

GROUP II These had had previous penicillin therapy and a definite or probable history of sensitivity or allergic reaction.

GROUP III These patients denied previous penicillin therapy and/or were unable to supply any data about it.

The study population included 4,677 patients who had had previous penicillin treatment without manifesting any apparent adverse reaction, 124 who had a history of penicillin hypersensitivity in the past, and 660 who had no recollection of previous penicillin treatment or could not remember what previous therapy they had received.

\section{Results}

When a skin test with PPL was performed, a positive reaction to the reagent occurred in 358 of 4,677 (7.7 per cent.) of the patients who had tolerated previous penicillin, in 41 of 124 (33.1 per cent.) who gave a history of sensitivity to penicillin, and in 22 of 660 ( 3.3 per cent.) who had no known history of penicillin or other therapy (Table I). These results are in agreement with those reported by Simpson (1963), Rytel, Klion, Arlander, and Miller (1963), VanArsdel, Tobe, and Pasnick (1963), Brown, Price, and Moore (1964), and Levine and Price (1964).

Over 90 per cent. of patients in Group I were given penicillin (Table II). Of the patients with a history of penicillin therapy and a negative skin test, 4,102 of 4,283 (95 per cent.) were challenged and, within 48 hours, five developed urticaria and generalized pruritus. 105 of 358 (29 per cent.) patients with a negative history of penicillin sensitivity and a positive intradermal test were challenged with penicillin and none developed an adverse reaction. However, no patient with a strong intradermal response was challenged.

TABLE I Division of patients into three groups

\begin{tabular}{|c|c|c|c|c|c|}
\hline Group & Therapy & Sensitivity & No. of patients & \multicolumn{2}{|c|}{ Positive reactors to $P P L$} \\
\hline $\mathbf{I}$ & Previous penicillin & Not sensitive & 4,677 & 358 & $7 \cdot 7$ \\
\hline II & Previous penicillin & Sensitive & 124 & 41 & $33 \cdot 1$ \\
\hline III & No previous penicillin & No data & 660 & 22 & $3 \cdot 3$ \\
\hline
\end{tabular}


Table II shows that, of 83 of the patients with a history of previous penicillin treatment and sensitivity, 36 with negative intradermal tests were challenged and one developed an allergic reaction (urticaria and pruritus) within 48 hours. In this same group, five patients with a positive history and positive intradermal tests were challenged with penicillin without untoward effect.

The majority of the 660 patients in Group III (Table II), including five with positive intradermal tests, were challenged with penicillin without incident.

\section{Adverse Reactions to PPL}

Penicilloyl-polylysine is not completely incapable of producing adverse reactions (Resnik and Shelley, 1966; Ettinger and Kaye, 1964). Of our 5,461 patients who received PPL intradermally (Table III), five developed systemic but not life-threatening reactions.

One patient showed marked erythema and oedema of the forearm around the skin test site $\mathbf{4 0}$ minutes after being tested; three patients developed generalized urticaria, 15, 25, and 30 minutes after receiving PPL; and one patient developed a generalized papulosquamous eruption which was delayed for 48 hours. Four of these five reactions to the test preparation occurred in patients who gave a history of penicillin hypersensitivity.

\section{Discussion}

The penicilloyl-polylysine used in this study appears to be relatively safe in that it did not per se produce any life-threatening reactions. Extensive experience proved it to produce very few ambiguous responses. During the study, the rate of adverse reactions to therapeutic penicillin was reduced to about 0.1 per cent., a decrease from 3.5 per cent. before the study period.

It was not considered proper to challenge with penicillin those patients whose PPL skin responses were strongly positive. Consequently, the study only indirectly corroborates previously published reports correlating positive skin tests with clinical penicillin allergy. The reduction of the adverse reaction rate to penicillin therapy in this clinic from 3.5 per cent. to approximately $0 \cdot 1$ per cent., suggests that the patients who would have reacted to the challenge were assigned to the group not treated because of their positive skin reactions. No immediate or anaphylactic type reactions were encountered in any of the challenged patients. None of the five reactions to penicillin therapy which occurred in patients with negative skin tests occurred immediately and none was dangerous to life. It is presumed that these patients reacted to an antigenic determinant other than penicilloyl, or that clinical hypersensitivity developed during the course of therapy. Prospective skin testing

TABLE II History, skin test reactions, and penicillin challenge

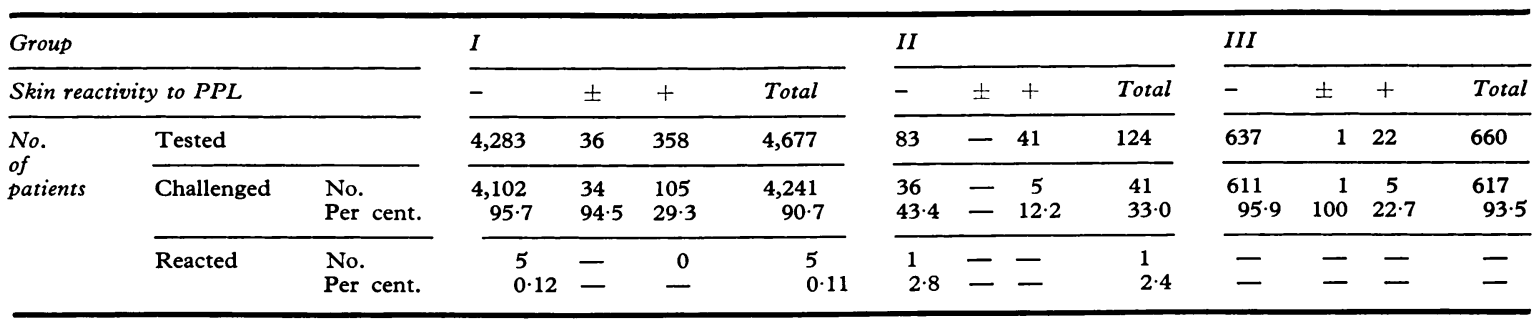

TABLE II Untoward reactions to skin test antigen in five patients

\begin{tabular}{|c|c|c|c|c|}
\hline Patient No. & Penicillin treatment & Penicillin hypersensitivity & Time interval before reaction & Type of reaction \\
\hline 1 & Yes & Yes & $40 \mathrm{~min}$. & $\begin{array}{l}\text { Local erythema } \\
\text { Oedema at test site }\end{array}$ \\
\hline 2 & Yes & Yes & $30 \mathrm{~min}$. & $\begin{array}{l}\text { Pruritus } \\
\text { Generalized urticaria }\end{array}$ \\
\hline 3 & Yes & Yes & $15 \mathrm{~min}$. & $\begin{array}{l}\text { Pruritus } \\
\text { Oedema } \\
\text { Generalized urticaria }\end{array}$ \\
\hline 4 & Yes & No & $25 \mathrm{~min}$ & $\begin{array}{l}\text { Local erythema } \\
\text { Oedema at test site } \\
\text { Generalized urticaria }\end{array}$ \\
\hline 5 & Yes & Yes & $48 \mathrm{hrs}$ & $\begin{array}{l}\text { Generalized papulosquamous } \\
\text { eruption }\end{array}$ \\
\hline
\end{tabular}


with penicilloyl-polylysine appears to be safe and useful in clinical work.

\section{Summary}

5,461 intradermal tests for penicillin hypersensitivity were performed using a new penicilloyl moiety combined with polylysine. This preparation gave more distinct skin responses than previous preparations (0.7 per cent. ambiguous intradermal test results compared with 46.6 per cent. with older preparations). Five adverse reactions were observed; four in the 124 patients who gave a history of penicillin treatment and hypersensitivity and one in a patient who had previously received penicillin without difficulty. Cutaneous reactivity to the test material was compared with the history of former adverse reactions to penicillin and with the effect of subsequent penicillin challenge. During the conduct of the study the rate of adverse reactions to therapeutic penicillin was limited to about $0 \cdot 1$ per cent.

The aid and competence of our colleagues, Dorothy $R$. Lynn, M.D., and Alfred M. DiGiacomo, M.D., in performing and interpreting the skin tests, is gratefully acknowledged.

\section{References}

Brown, B. C., Price, E. V., and Moore, M. B. (1964) F. Amer. med. Ass., 189, 599

EtTINGER, E., and KAYE, D. (1964) N. Engl. F. Med., 271, 1105

Levine, B. B. (1960) f. exp. Med., 112, 1131

- and OvarY, Z. (1961) Ibid., 114, 875

- and PrICE, V. H. (1964) Immunology, 7, 542

PARker, C. W., Kern, M., and EISEN, H. N. (1962b) $\mathcal{F}$. exp. Med., 115, 789

-, Shapiro, J., Kern, M., and Eisen, H. N. (1962c)

Ibid., 115, 821
- WeCK, A. L. DE, KerN, M., and EISEN, H. N. (1962a) Ibid., 115, 803

Resnik, S. S., and Shelley, W. B. (1966) F. Amer. med. Ass., 196, 740

Rytel, M. W., Klion, F. M., Arlander, T. R., and MILlER, L. F. (1963), Ibid., 186, 894

Simpson, W. G. (1963) 'Penicillin Reactions' in 'Proceedings of XII International Congress of Dermatology, Washington, D.C. 1962', p. 897. Excerpta Medica Foundation, Amsterdam (Int. Congr. Ser., No. 55)

VanArsdel, P. P., JR., Tobe, A. D., and Pasnick, L. J. (1963) f. Allergy, 34, 526.

WECK, A. L. DE (1962a) Int. Arch. Allergy, 21, 20

- (1962b) Dermatologica (Basel), 125, 283

- and Blum, C. (1963) Praxis, 52, 67

- and EISEN, H. N. (1960) f. exp. Med., 112, 1227

L'intra-dermo réaction à la pénicilloyl-polylysine dans l'estimation de la sensibilisation à la pénicilline

SOMMAIRE

5.461 épreuvres intra-dermiques pour la recherche de la sensibilisation à la pénicilline furent effectuées avec une nouvelle demi-molécule de pénicilloyl combinée avec la polylysine. Cette préparation a donné des réponses cutanées plus franches que les préparations précédentes $(0,7$ pour cent de résultats ambigus de l'épreuve intradermique contre 46,6 pour cent avec les préparations antérieures). On a observé 5 incidents: 4 parmi les 124 malades dans les antécédents desquels était mentionné un traitement à la pénicilline et une sensibilisation et $1 \mathrm{chez}$ un malade qui avait reçu antérieurement de la pénicilline sans ennui. La réponse cutanée au produit testé a été comparée avec des antécédents d'incidents à la pénicilline et avec l'effet d'un nouveau traitement à la pénicilline. Pendant le cours de cette étude, le taux des incidents au traitement pénicilliné ne dépassa pas 0,1 pour cent environ. 